\title{
Cerebrospinal fluid absorption in primary hypoparathyroidism
}

\author{
M. A. S A M B R O O K A N D L. F. H I L L \\ From the Departments of Neurology and Medicine, Manchester Royal Infirmary, Manchester
}

SUMMARY Cerebrospinal fluid absorption has been studied in a patient with primary hypoparathyroidism, papilloedema, and epilepsy. A marked reduction of cerebrospinal fluid transport into plasma was demonstrated which returned to normal after correction of the hypocalcaemia.

Papilloedema is an established complication of both primary and secondary hypoparathyroidism (Grant, 1953; Palmer et al., 1959). An increase in intracranial pressure has been demonstrated in most of the reported cases, and the condition has been grouped with various other disorders which may present with 'benign' intracranial hypertension. It has been suggested that idiopathic benign intracranial hypertension is due to a reduction in the absorption of cerebrospinal fluid into plasma (Bercaw and Greer, 1970; Johnston and Patterson, 1974).

The purpose of the present communication is to report a patient with primary hypoparathyroidism in whom an assessment of CSF transport into plasma by ${ }^{131}$ I RISA scanning has been made.

\section{Case report}

The patient, a 23 year old male, was admitted to hospital for investigation of epilepsy. Two years previously, while serving in the army, he had had two grand mal convulsions for which he had been investigated at a military hospital and started on anticonvulsant therapy. His epilepsy was poorly controlled, and after being discharged from the army he experienced intermittent blurring of vision, a persistent frontal headache, and difficulty with memory and concentration. Shortly before his second hospital admission he began to have attacks of spontaneous contraction of the muscles of the left hand.

There was no past medical history of significance

Address for reprint requests: Dr M. A. Sambrook, Department of Neurology, Withington Hospital, Manchester M20 8LR, England. Accepted 6 June 1977 and, in particular, no history of surgery to his neck.

EXAMINATION The patient gave an incoherent history and most of the details were obtained from his mother. His speech was slow and interrupted by long pauses for thought. Physical examination revealed that Chvostek's and Trousseau's signs were positive. There were bilateral post-polar cataracts, and visual acuity was reduced to $6 / 9$ and N.8. in both eyes. Examination of the optic fundi showed papilloedema and engorged retinal veins. He had normal muscle power and tone in all limbs; the plantar responses were flexor but all of the tendon reflexes were absent. Sensory testing was normal.

BIOCHEMICAL INVESTIGATIONS The serum calcium was $0.89 \mathrm{mmol} / 1$, phosphorus $2.27 \mathrm{mmol} / 1$, and magnesium $0.50 \mathrm{mmol} / \mathrm{l}$. Parathormone could not be detected in the serum. Estimations of blood urea and electrolytes, liver function tests, and serum proteins and electrophoresis were normal.

RADIOLOGY Plain radiography of the chest, hands, and skull were normal. Computed tomography of the head showed small lateral and third ventricles but was otherwise within normal limits.

ELECTROPHYSIOLOGY The electrocardiograph showed a prolonged Q-T interval of $0.4 \mathrm{~s}$ (heart rate, $70 / \mathrm{min}$ ) and tall peaked $T$ waves. The electroencephalogram was diffusely abnormal with a poorly formed alpha rhythm and widespread, persistent medium voltage theta and delta activity.

CEREBROSPINAL FLUID The lumbar CSF pressure 
was $220 \mathrm{mmH}_{2} \mathrm{O}$ with a protein concentration of $0.01 \mathrm{~g} / 1$ and a normal cell count.

Plasma absorption of CSF was assessed by radio-iodinated serum albumin (131I RISA) cisternography. One hundred microcuries of 131I RISA was introduced into the CSF by cisternal puncture and blood samples were collected at 1, 2, 4, 10,20,28, 48, 60,72, and 84 hours after injection to measure its rate of appearance in plasma. This was expressed as a percentage of the injected cisternal dose in total plasma volume using a standard to allow for the half-life of ${ }^{131}$ I and calculating the plasma volume from weight tables (Dagher et al., 1965). The maximum plasma radioactivity was $33.8 \%$ and occurred 72 hours after injection into the CSF (Figure).

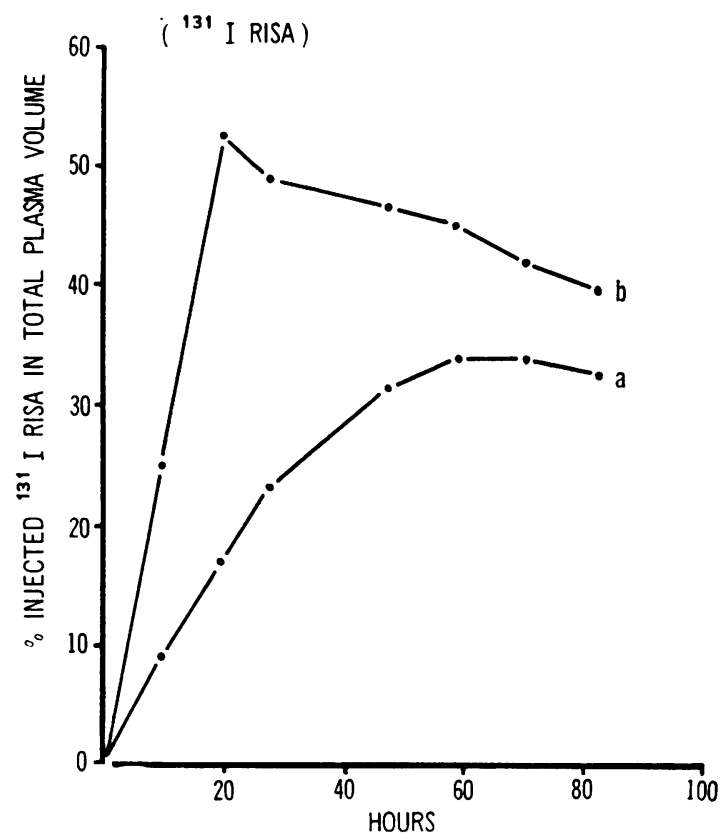

Figure Rate of appearance of cisternally injected ${ }^{131}$ I RISA in plasma (a) during hypocalcaemia, and (b) nine months after correction of the serum calcium.

\section{PROGRESS}

The patient was treated with a calcium supplement and $1 \mu \mathrm{g}$ 1.25-dihydroxycholecalciferol daily (Hill et al., 1976). On this therapy the serum calcium increased over the next three months to $2.25 \mathrm{mmol} / 1$ with a serum phosphorus of $1.57 \mathrm{mmol} / 1$ and serum magnesium of 0.67 $\mathrm{mmol} / \mathrm{l}$. The papilloedema resolved, and his memory and intellectual performance improved. The ECG and EEG returned to within normal limits, and a further lumbar puncture showed that the CSF pressure had decreased to $80 \mathrm{mmH}_{2} \mathrm{O}$.

Nine months after correction of the serum calcium a further assessment of cerebral ventricular size by computer tomography revealed that they were still small and had not enlarged. ${ }^{131}$ I RISA cisternography was repeated and now showed a maximum plasma radioactivity of $52.7 \%$ occurring 20 hours after injection (Figure).

Anticonvulsant therapy was discontinued and the patient has had no further epileptic fits.

\section{Discussion}

The patient presented to the Department of Neurology at Manchester Royal Infirmary with a two year history of convulsions, muscle cramps, and mental slowing, and it was subsequently shown that he had the classical clinical and biochemical features of hypoparathyroidism. He also had papilloedema which resulted from raised intracranial pressure in the absence of a space-occupying lesion. Correction of his hypocalcaemia with vitamin $\mathrm{D}$ and calcium supplements was associated with a full clinical and symptomatic recovery and the resolution of his papilloedema.

The association of papilloedema and hypoparathyroidism was first described by Luttwig in 1903. In a review of the literature Palmer et al. (1959) were able to find 32 previously reported cases and added a further two of their own. These authors stressed that although the association was rare its presentation with convulsions and mental changes often led to the erroneous diagnosis of a cerebral tumour. In most cases an increase in intracranial pressure was confirmed but the mechanism of this has remained unclear. Albrecht (1923) suggested that the papilloedema was due to generalised cerebral swelling and quoted necropsy studies which showed widespread oedematous changes in the brain. Ellis (1928) confirmed this experimentally when he demonstrated an increase in the water content of the brain in parathyroidectomised cats. The osmotic effect of changes in CSF and plasma electrolytes was considered by Grant (1953) but he concluded that the changes which occurred were small and probably not significant.

Movement of albumin from CSF to plasma is dependent upon bulk flow of CSF through the arachnoid granulations into the dural venous sinuses (Davson et al., 1973), and, in the absence of hydrocephalus, the appearance in plasma of cisternally injected ${ }^{131}$ I RISA is a reliable indicator of CSF absorption. The rate of appearance 
has been established in normal subjects by Abbott and Alksne (1968) who found plasma values 24 hours after injection ranging from 41 to $60 \%$ (mean $48 \%$ ) of the total cisternal dose. These values are similar to those obtained in dogs where the plasma level of ${ }^{131}$ I RISA increases steadily to a point of equilibrium 16 to 24 hours after injection (van Wart et al., 1960; Abbott and Alksne, 1968 ). In the patient studied, only $16 \%$ of the cisternally injected ${ }^{131}$ I RISA had appeared in the plasma after 20 hours and equilibrium was not achieved until 72 hours. Nine months after correction of his serum calcium the rate of appearance had increased to $53 \%$ with equilibrium at 20 hours. It has been suggested that the CSF volume is increased in patients with benign intracranial hypertension (Davidoff, 1956; Greer, 1968; Siegel and Spackman, 1972) but in this patient computed tomography did not show any detectable change in the ventricular size or prominence of the subarachnoid spaces after treatment. While this does not rule out smaller changes in the size of the basal subarachnoid cisterns it certainly indicates that any change in volume was small and could not account for the marked increase in the rate of appearance of ${ }^{131}$ I RISA in the plasma. These results are consistent with a marked reduction in CSF absorption during the period of hypocalcaemia.

A similar reduction in CSF absorption has been recorded previously in two patients with idiopathic benign intracranial hypertension by Bercaw and Greer (1970). From a study of six similar patients, Johnston and Patterson (1974) demonstrated a delay in CSF circulation using isotope cisternography, and in one of these patients they confirmed a reduction in the rate of CSF absorption by showing a delayed recovery from urine of cisternally injected Indium ${ }^{111}$ DTPA. The pathological changes causing a reduction in CSF absorption are not known. In hypoparathyroidism, however, the observations of Baker et al. (1969) may be important. Using the giant squid axon they demonstrated a reduction in the rate of efflux of intracellular sodium in the presence of decreased extracellular calcium. It remains debatable whether the movement of CSF through the arachnoid villi is by a process of vacuolation or through continuous channels, but an increase in intracellular sodium and water in the arachnoid villi could interfere with either of these mechanisms. The results of the present study indicate that correction of the hypocalcaemia is associated with a return to normal of CSF absorption.
We are grateful to Dr L. A. Liversedge and to Professor P. Adams for permission to study this patient, and to Dr M. Critchley of the Department of Medical Physics for arranging the isotope studies.

\section{References}

Abbott, M., and Alksne, J. F. (1968). Transport of intrathecal ${ }^{125}$ I RISA to circulating plasma. A test for communicating hydrocephalus. Neurology (Minneapolis), 18, 870-874.

Albrecht, K. (1923). Strauungspapille bei Tetanie. Monatsschrift für Psychiatrie und Neurologie, 55, $55-62$.

Baker, P. F., Blaustein, M. P., Hodgkin, A. L., and Steinhardt, R. A. (1969). The influence of calcium on sodium efflux in squid axons. Journal of Physiology, 200, 431-458.

Bercaw, L. B., and Greer, M. (1970). Transport of intrathecal ${ }^{131}$ I RISA in benign intracranial hypertension. Neurology (Minneapolis), 20, 787-790.

Dagher, F. J., Lyons, J. H., Finlayson, D. C., Shamsai, J., and Moore, F. D. (1965). Blood volume measurement: a critical study. Advances in Surgery, 1, 69-109.

Davidoff, L. M. (1956). Pseudotumor cerebri benign intracranial hypertension. Neurology (Minneapolis), 6, 605-615.

Davson, H., Dormer, F. R., and Hollingsworth, J. R. (1973). The mechanism of drainage of the cerebrospinal fluid. Brain, 96, 329-336.

Ellis, M. M. (1928). Water content of certain tissues during acute guanidine and parathyroprivia tetanies. Biochemistry Journal, 22, 937-940.

Grant, D. K. (1953). Papilloedema and fits in hypoparathyroidism. Quarterly Journal of Medicine, 22, 243-259.

Greer, M. (1968). Management of benign intracranial hypertension (Pseudotumor cerebri). Clinical Neurosurgery, 15, 161-174.

Hill, L. F., Davies, M., Taylor, C. M., and Stanbury, S. W. (1976). Treatment of hypoparathyroidism with 1,25-dihydroxycholecalciferol. Clinical Endocrinology. 5, 167s-173s.

Johnston, I., and Patterson, A. (1974). Benign intracranial hypertension. II CSF pressure and circulation. Brain, 97, 301-312.

Luttwig, G. (1903). Ein Fall von chronischer Tetanie. (Inaug. Diss.) München.

Palmer, R. F., Searles, H. H., and Boldrey, E. B. (1959) Papilledema and hypoparathyroidism simulating brain tumor. Journal of Neurosurgery, 16. 378-384.

Siegel, N. J., and Spackman, T. J. (1972). Chronic hypervitaminosis A with intracranial hypertension and low cerebrospinal fluid concentration of protein. Clinical Paediatrics, 11, 580-584.

van Wart. C. A., Dupont, J. R., and Kraintz, L. (1960). Transport of radioiodinated human serum albumin from cerebrospinal fluid to blood plasma. Proceedings of the Society of Experimental Biology (New York), 103, 708-710. 